\title{
Depressive Mood and Suicide Among Middle-Aged Workers: Findings from a Prospective Cohort Study in Nagoya, Japan
}

\author{
Akiko Tamakoshi ${ }^{1}$, Yoshiyuki Ohno ${ }^{1}$, Takuji Yamada ${ }^{2}$, Kunio Aoki ${ }^{3}$, Nobuyuki Hamajima ${ }^{4}$, \\ Masaya Wada ${ }^{5}$, Takashi Kawamura ${ }^{6}$, Kenji Wakai ${ }^{1}$, and Ying Song Lin ${ }^{1}$
}

\begin{abstract}
Background: In Japan, mortality from suicide has peaked around 50 years old among men, with increasing trend after 65 years old, and this peak became more apparent in recent years. Beside this, "psychological autopsy" has revealed depression as one of the most important risk factors for suicide. There is, however, no cohort study which examined the relationship between depressive mood measured by simple method and suicide in middle-aged general population.

Methods: In 1989, baseline information was collected by a self-administered questionnaire, and 18,450 workers were followed up to March 31, 1995. All deaths observed during active service were identified, and when retired, its date was recorded. Among 5,352 male workers aged between 40 to 54,11 committed suicide during follow-up period of 5 years. Analysis were carried out by Cox's proportional hazard model, controlling for age.

Results: Those who slept 9 hours or more per night demonstrated 12.14-fold risk of suicide compared with those who slept less than 9 hours. Smokers were more likely to commit suicide than non-smokers. Those who answered affirmatively to more than 7 out of 12 questions, which were derived from Zung self-rating depression scale, experienced an increased risk of suicide (RR 9.95; 95\% Cl: $1.89-52.44)$, even after adjusting for other confounding factors.

Conclusion: We found an association between depressive mood and subsequent suicide in a middle-aged workers. Detailed observation and follow-up of those with depressive mood should be systematically organized with due attention and caution. J Epidemiol, 2000;10:173-178
\end{abstract}

suicide, depressive mood, cohort study, risk factors

\section{INTRODUCTION}

Suicide was the seventh cause of certified death in 1994 in Japan, accounting for $2.4 \%$ of total deaths, with the mortality rate of 16.9 per 100,000 population ${ }^{12}$. Among young adults in particular, suicide accounted for much larger proportion of deaths; $22.3 \%$ ( 1 st cause of death), $17.4 \%$ ( $2 \mathrm{nd}$ ), and $11.8 \%$ (3rd) in those aged 30-34, 35-39, and 40-44 years old, respectively. Age-specific mortality rate from suicide clearly peaked around 50 years old among men with increasing trend after
65 years old, and this peak became more apparent in recent years ${ }^{1)}$. It is, therefore, of importance and significance to disclose possible risk factors of suicide among middle-aged population in Japan.

The most common study design to find out the causes of suicide is the "psychological autopsy"; a case-control study in which inquires are retrospectively made about abnormal behaviors or symptoms observed before death, and from the studies used this design, depression was found as one of the most important risk factors for suicide ${ }^{2}$. An association of

Received June 23, 1999 ; accepted October 6, 1999.

${ }^{1}$ Department of Preventive Medicine, Nagoya University, School of Medicine, Nagoya Japan.

${ }^{2}$ Aichi Medical School Japan.

${ }^{3}$ Aichi Cancer Center, Nagoya Japan.

${ }^{4}$ Division of Epidemiology, Aichi Cancer Center Research Institute, Nagoya Japan.

${ }^{5}$ Nagoya City Office, Nagoya Japan.

${ }^{6}$ Kyoto University Center for Student Health, Kyoto Japan.

Address for correspondence : Akiko Tamakoshi, Department of Preventive Medicine, Nagoya University, School of Medicine, 65 Tsurumai-cho, Showa-ku, Nagoya 466-8550 Japan. 
depression with suicide was also disclosed by some cohort studies in recent years, most of which, however, followed-up psychiatric patients, since suicide rate is well-known to be much higher among patients with depressive disorders than among the general population ${ }^{3}$. There is only one cohort study which examined a relationship between depression at the baseline and subsequent suicide in the general population of the elderly ${ }^{4}$. To our best knowledge, such cohort study has never been conducted among the middle-aged general population.

In 1989, we defined and started to follow up the civil-service-workers to explore possible associations of several lifestyle factors with such diseases as cancers/ circulatory diseases and other life-threatening events as well. In this communication, a relationship between self-reported depressive mood measured by simple method and subsequent suicide will be examined in this cohort, using the 5-years follow-up data.

\section{MATERIAL AND METHODS}

\section{Study cohort}

In September 1989, baseline information were collected by a self-administered questionnaire from 18,708 civil-serviceworkers (response rate $: 95.5 \%$ ) in one city. From these 18,708 workers, 258 individuals with missing information on occupational identification number, which was a key-code for our follow-up study, were excluded, and then, we started to follow-up the remaining 18,450 workers (11,475 men and 6,975 women).

Information collected by a self-administered questionnaire included past history of major diseases, current health status, family history of major diseases, smoking and drinking habits, mental status and others. In the present analysis, we limited cohort members to those aged from 30 to 54 years. This limitation is based on the following two reasons; firstly, suicide rate is known to rise after 30 years old in Japan, and secondly, the age at retirement is 60 years old in this workplace (workers aged 55 years or more at baseline survey would all retire during the follow-up period of 5 years). As a consequence, the cohort examined in this analysis consisted of 13,294 workers ( 8,783 men and 4,511 women), with age distribution at baseline as shown in Table 1.

\section{Depression scale}

To assess mental status within current 1 month, 12 question items, which were derived from the Zung self-rating depression scale (SDS) ${ }^{5}$, were used. There were 3 large diagnostic criteria established by Zung ${ }^{5}$, from which we derived the items: 1 of 2 pervasive affect items, 6 of 8 physiological equivalents items and 7 of 10 psychological equivalents items. Answers were expressed as one of three forced-choice responses: "none", "sometimes" and "most or all times", though four response categories were adopted in the original SDS. Positive phrase questions in the original SDS were translated into negative ones. This implied that "most or all times" definitely denoted depressive mood in this modified questionnaire. Total depression score was obtained as a sum of the 12 question items which were scored either 0 or $1 ; 0$ to be "none" and 1 to be "sometimes" or "most or all times" (the total depression score then ranged from 0 to 12: 0 indicates free from depressive mood). All cohort members were divided into two groups by this total depression score (depressive group: more than 20 percentile of the members, that is, score of 8 or more, normal group: 20 percentile or less, that is, score of 7 or lower).

\section{Follow-up}

Study population of 13,294 workers was followed up until March 31, 1995 in this analysis. For all deceased subjects, a direct cause of death with the date at death was identified among those who were continuously on active service. When retired, the date at retirement was also recorded. By March 31, 1995, 92 cohort members (76 men and 16 women) died. Among 92 deaths, 11 (9 men and 2 women) (12.0\%) were due to suicide. During the follow-up period of 5 years, 847 members ( 479 men and 368 women) (6.4\%) retired from their works.

\section{Statistical Methods}

Analysis was carried out by applying Cox's proportional hazard model controlling for age and sex distribution. All deceased subjects not from suicide and the retired were treated as censored when the events occurred. All statistical analyses were conducted using the SAS programs at Nagoya University Computation Center.

Table 1. Sex and age distribution of the subjects whose age were between 30 and 54 at baseline.

\begin{tabular}{ccrrrrrr}
\hline & & $30-34$ & $35-39$ & $40-44$ & $45-49$ & $50-54$ & total \\
\hline \multirow{2}{*}{ men } & number & 1409 & 2022 & 1972 & 1884 & 1496 & 8783 \\
& $\%$ & 16.0 & 23.0 & 22.5 & 21.5 & 17.0 & 100.0 \\
\multirow{2}{*}{ women } & number & 783 & 1098 & 1045 & 875 & 710 & 4511 \\
& $\%$ & 17.4 & 24.3 & 23.2 & 19.4 & 15.7 & 100.0 \\
\hline
\end{tabular}




\section{RESULTS}

Sex- and age-specific mortality rates from suicide are shown in Table 2. Men experienced higher suicide rate than women. No suicide happened among those aged 30-39 years during the follow-up period, and only 2 suicides occured in women, analyses were limited to men those aged 40 years old or more at baseline.

Table 3 summarizes adjusted relative risks (hazard ratios) for suicide by life-style factors and total depression score among men aged between 40 to 54 years at baseline. When age were adjusted, sleeping hour was found to be significantly related to suicide risk. Those who reported to sleep 9 hours or more per night were 11.49 -times (95\% CI: $2.38-55.34$ ) more likely to die from suicide, as compared to those who reported less than 9 hours. Smokers experienced 7.57-times higher suicide risk than non-smokers, though with borderline significance. Not married were at a marginally significant risk factor of suicide. Drinking habit, coffee consunption and job title were all unrelated with suicide risk. Those with total depression score of 8 or more were found to be at 8.15-times (95\% CI: 2.04-32.61) elevated risk relative to those with the total score of 7 or less.

When analyzed further paying attention to each question item, 10 out of 12 question items were found to be significant-

Table 2. Sex and age specific suicide mortality among those whose age were between 30 and 54 at baseline

\begin{tabular}{llrrrrrrr}
\hline \multirow{2}{*}{ men } & $30-34$ & $35-39$ & $40-44$ & $45-49$ & $50-54$ & $55+$ & \multicolumn{1}{c}{ total } \\
\cline { 2 - 2 } & person-year & 3353.8 & 8985.7 & 12092.1 & 9786.4 & 9479.5 & 4237.5 & 47935.0 \\
& suicide & 0 & 0 & 1 & 5 & 3 & 0 & 9 \\
\multirow{2}{*}{ women } & mortality* & 0.0 & 0.0 & 8.3 & 51.1 & 31.6 & 0.0 & 18.8 \\
& person-year & 1855.7 & 4678.9 & 6292.4 & 5115.6 & 4307.9 & 2049.5 & 24300.0 \\
& suicide & 0 & 0 & 0 & 2 & 0 & 0 & 2 \\
& mortality* & 0.0 & 0.0 & 0.0 & 39.1 & 0.0 & 0.0 & 8.2 \\
\hline
\end{tabular}

* suicide moratlity per 100,000 person-years

Table 3. Hazard ratios of suicide among men those aged between 40 and 54 years at baseline.

\begin{tabular}{|c|c|c|c|c|c|c|c|}
\hline & \multirow[b]{2}{*}{ number } & \multirow[b]{2}{*}{ person-year } & \multirow[b]{2}{*}{$\begin{array}{c}\text { number } \\
\text { of } \\
\text { suicide }\end{array}$} & \multicolumn{2}{|c|}{ adjusted for age } & \multicolumn{2}{|c|}{ multivariate\$ } \\
\hline & & & & $\begin{array}{l}\text { Hazard } \\
\text { ratio }\end{array}$ & $\begin{array}{c}95 \% \text { Confidence } \\
\text { interval }\end{array}$ & $\begin{array}{l}\text { Hazard } \\
\text { ratio }\end{array}$ & $\begin{array}{c}95 \% \text { Confidence } \\
\text { interval }\end{array}$ \\
\hline \multicolumn{8}{|l|}{ Sleeping hours } \\
\hline$<9$ hrs/night & 5,166 & $27,082.6$ & 7 & 1.00 & & 1.00 & \\
\hline$\geq 9$ hrs/night & 128 & 696.5 & 2 & 11.49 & $2.38-55.34 * *$ & 12.14 & $1.35-108.98 *$ \\
\hline \multicolumn{8}{|l|}{ Drinking habits } \\
\hline drinker & 4,274 & $23,219.4$ & 6 & 0.49 & $0.12-1.96$ & 0.29 & $0.06-\quad 1.37$ \\
\hline non-drinker & 1,046 & $5,694.7$ & 3 & 1.00 & & 1.00 & \\
\hline \multicolumn{8}{|l|}{ Smoking habits } \\
\hline smoker & 2,737 & $14,832.7$ & 8 & 7.57 & $0.95-60.53 \#$ & 9.78 & $1.00-95.46 *$ \\
\hline non-smoker & 2,578 & $14,059.4$ & 1 & 1.00 & & 1.00 & \\
\hline \multicolumn{8}{|c|}{ Coffee consumption } \\
\hline$\geq 1$ cup/day & 4,222 & $22,968.6$ & 6 & 0.51 & $0.13-2.09$ & 0.33 & $0.06-\quad 1.87$ \\
\hline$<$ lcup/day & 1,087 & $5,887.2$ & 3 & 1.00 & & 1.00 & \\
\hline \multicolumn{8}{|l|}{ Marital status } \\
\hline married & 4,648 & $25,290.1$ & 6 & 1.00 & & 1.00 & \\
\hline others & 318 & $1,718.1$ & 2 & 4.91 & $0.98-24.58 \#$ & 1.37 & $0.16-11.72$ \\
\hline \multicolumn{8}{|l|}{ Job title } \\
\hline white-collor & 3,134 & $17,002.8$ & 4 & 1.00 & & 1.00 & \\
\hline others & 1,901 & $10,373.9$ & 4 & 1.67 & $0.42-6.74$ & 1.19 & $0.26-\quad 5.47$ \\
\hline \multicolumn{8}{|c|}{ Total depression score } \\
\hline$\leq 7$ & 4,061 & $22,060.4$ & 3 & 1.00 & & 1.00 & \\
\hline$\geq 8$ & 1,003 & $5,449.7$ & 6 & 8.15 & $2.04-32.61 * *$ & 9.95 & $1.89-52.44 * *$ \\
\hline
\end{tabular}

Totals may differ due to missing information

$\$$ : adjusted for age, and each of the other variables in the table

$\# ; \mathrm{p}<0.1, * ; \mathrm{p}<0.05, * * ; \mathrm{p}<0.01$ 
Table 4. Hazard ratio of suicide by 12 question items for depression among men those aged between 40 and 54 years at baseline.

\begin{tabular}{|c|c|c|c|c|c|}
\hline & number & person-year & number of suicide & Hazard ratio ${ }^{1)}$ & 95\% Confidence interval \\
\hline \multicolumn{6}{|c|}{ I feel down hearted } \\
\hline most/ all times & 226 & $1,229.2$ & 3 & 12.69 & $2.55-63.08 * *$ \\
\hline sometimes & 2,190 & $11,955.3$ & 3 & 1.30 & $0.26-\quad 6.43$ \\
\hline never & 2,837 & $15,364.1$ & 3 & 1.00 & \\
\hline \multicolumn{6}{|c|}{ I have touble sleeping through the night } \\
\hline most/ all times & 153 & 834.1 & 2 & 22.21 & $3.13-157.66 * *$ \\
\hline sometimes & 1,699 & $9,259.4$ & 5 & 5.01 & $0.97-25.83$ \\
\hline never & 3,415 & $18,533.3$ & 2 & 1.00 & \\
\hline \multicolumn{6}{|c|}{ I have trouble with constipation } \\
\hline most/ all times & 152 & 830.1 & 1 & 3.92 & $0.48-31.97$ \\
\hline sometimes & 892 & $4,847.2$ & 1 & 0.67 & $0.08-\quad 5.48$ \\
\hline never & 4,217 & $22,916.1$ & 7 & 1.00 & \\
\hline \multicolumn{6}{|c|}{ My heart beats faster } \\
\hline most/ all times & 33 & 173.0 & 1 & 31.94 & $3.57-285.77 * *$ \\
\hline sometimes & 1,106 & $5,997.9$ & 4 & 3.71 & $0.93-14.84$ \\
\hline never & 4,103 & $22,316.4$ & 4 & 1.00 & \\
\hline \multicolumn{6}{|c|}{ I get tired with no reason } \\
\hline most/ all times & 275 & $1,469.5$ & 4 & 14.55 & $3.24-65.39 * * *$ \\
\hline sometimes & 2,086 & $11,349.9$ & 2 & 0.93 & $0.16-\quad 5.56$ \\
\hline never & 2,885 & $15,688.1$ & 3 & 1.00 & \\
\hline \multicolumn{6}{|c|}{ I feel that others would be better off if I were dead } \\
\hline most / all times & 47 & 246.0 & 2 & 40.56 & $7.86-209.20 * * *$ \\
\hline sometimes & 549 & $2,996.4$ & 2 & 3.37 & $0.65-17.35$ \\
\hline never & 4,634 & $25,175.9$ & 5 & 1.00 & \\
\hline \multicolumn{6}{|c|}{ I feel worst in the morning } \\
\hline most/ all times & 186 & $1,014.0$ & 3 & 15.13 & $3.36-68.11 * * *$ \\
\hline sometimes & 1,400 & $7,604.1$ & 2 & 1.33 & $0.24-\quad 7.30$ \\
\hline never & 3,660 & $19,890.5$ & 4 & 1.00 & \\
\hline \multicolumn{6}{|c|}{ I do not feel hopeful about the future } \\
\hline most/ all times & 243 & $1,309.7$ & 4 & 19.32 & $4.31-86.61 * * *$ \\
\hline sometimes & 1,544 & $8,442.4$ & 2 & 1.49 & $0.25-\quad 8.91$ \\
\hline never & 3,447 & $18,699.4$ & 3 & 1.00 & \\
\hline \multicolumn{6}{|c|}{ I find it difficult to make decisions } \\
\hline most/ all times & 162 & 874.5 & 3 & 24.63 & $4.09-148.23 * * *$ \\
\hline sometimes & 2,487 & $13,563.4$ & 4 & 2.10 & $0.39-11.49$ \\
\hline never & 2,602 & $14,097.5$ & 2 & 1.00 & \\
\hline \multicolumn{6}{|c|}{ I do not feel that I am useful } \\
\hline most/ all times & 205 & $1,115.4$ & 2 & 33.34 & $3.02-368.23 * *$ \\
\hline sometimes & 1,601 & $8,720.1$ & 6 & 12.66 & $1.52-105.21 *$ \\
\hline never & 3,404 & $18,478.2$ & 1 & 1.00 & \\
\hline \multicolumn{6}{|l|}{ My life is not full } \\
\hline most/ all times & 221 & $1,202.5$ & 3 & 38.65 & $4.01-372.86 * *$ \\
\hline sometimes & 2,190 & $11,939.1$ & 5 & 6.42 & $0.75-54.98$ \\
\hline never & 2,794 & $15,142.1$ & 1 & 1.00 & \\
\hline \multicolumn{6}{|c|}{ I am not satisfied with the life } \\
\hline most/ all times & 401 & $2,192.4$ & 2 & 4.34 & $0.73-26.01$ \\
\hline sometimes & 2,179 & $11,891.0$ & 4 & 1.61 & $0.36-\quad 7.20$ \\
\hline never & 2,627 & $14,211.5$ & 3 & 1.00 & \\
\hline
\end{tabular}

" adjusted for age

$* ; \mathrm{p}<0.05, * * ; \mathrm{p}<0.01, * * * ; \mathrm{p}<0.001$ 
ly related with a elevated risk for suicide (Table 4). Two questions which showed the highest risk, when affirmatively answered, were "I feel that others would be better off if I were dead" (40.56, 7.86-209.20), and "my life is not full" (38.65, 4.01-372.86). Two questions insignificantly linked with suicide risk were "I have trouble with constipation" and "I am not satisfied with the life", though their hazard ratios were larger than 3.00 .

The result obtained by a multivariate analysis is also included in Table 3 . When all other mutually confounding factors were taken into account, those with total depression score of 8 or more showed 9.95- fold risk. Sleeping 9 hours or more per night and smoking remained as a significant risk factor for suicide.

\section{DISCUSSION}

This study followed-up civil-service-workers for 5 years. Since the most workers should be retired from this work place at 60 years old, we limited the workers in the present analysis to those under 54 years old at the start point: resulted in dropout rate of only $6.4 \%$.

In our study, depressive mood was measured by 12 question items which were derived from the SDS ${ }^{5}$, with some modification, which has been widely used in normal populations, though originally devised for depressed patients ${ }^{6)}$. In Japan, as Kawakami and his colleagues indicated ${ }^{7}$, SDS is well validated and widely used. Since in our cohort study, we collected so many kinds of information by a self-administered questionnaire, then we could not help to limit the number of questions for measuring depressive mood by selecting 12 questions form original SDS.

A critical issue is, therefore, whether 12 questions selected could adequately measure depressive mood in this middle aged workers. First, 12 items covered the 3 large diagnostic criteria of depression established by Zung ${ }^{5}$. Second, the internal consistencies (Cronbach's alphas) of the total depression score was high; 0.84 for men and 0.82 for women aged between 30 and 54 years old. Third, to confirm external validity, we compared the total depression score with the Center for Epidemiologic Research Depression Scale (CES-D) and original SDS among 66 subjects ( 41 men and 25 women; age ranged 30 to 54) working in this workplace at 1997 . The pearson correlation with the total depression score were $0.65(\mathrm{p}<0.0001)$ and 0.55 $(\mathrm{p}<0.0001)$ for CES-D and original SDS, respectively. The subjects with 8 or more total depression score, i.e. depressive group identified from the modified SDS, had significantly higher scores of CES-D (18.15 vs. 8.77; $<<0.01)$ and original SDS ( 44.31 vs. $36.09 ; \mathrm{p}<0.0001$ ), respectively, than those with lower total depression score. Then it would be reasonably plausible to use 12 questions from the original ones to measure individual depressive mood in this workers' cohort.

Depression has been incriminated for suicide as a primary risk factor ${ }^{2)}$, but there is no cohort study which has disclosed this relationship in middle-aged general population in particular. Most cohort studies, which aimed to explore an association of depression with suicide, examined the psychiatric patients $8.9,10$ ), except one cohort study which studied the elderly population ${ }^{4}$. In our analysis, we could find the significant association of baseline depressive mood with subsequent suicide in the middle-aged workers, though the depression measured at the certain time would disappear or vary the degree in several years, and among non-patient population, depression was reported to last over eight months ${ }^{11)}$.

Many studies reported possible risk factors for suicide, other than depression, among the middle-aged general population ${ }^{12-22)}$. Possible risk factors incriminated in these studies included mental disorder ${ }^{12}$, hostility ${ }^{13}$, habits of nervous tension ${ }^{14)}$, low income ${ }^{16)}$, cigarette smoking ${ }^{15}$, 16), alcohol consumption ${ }^{17}$, lower coffee consumption ${ }^{18,22)}$, hormone replacement therapy ${ }^{19)}$ and low serum cholesterol concentration ${ }^{20,21}$.

The present study found longer sleeping hour as a significant risk factor. According to Ross et al. who followed-up the elderly population, sleeping 9 hours or more per night was also found to be a significant risk factor for suicide ${ }^{4}$, likewise our study. Though Bliwise and his colleagues ${ }^{23)}$ pointed out that self-reported sleeping hour itself was affected by depression, the relationship was remained even after adjusting for depressive mood. However, how longer-sleeping hour would be related to subsequent suicide is unclear in term of bio-mechanism. Furthermore, having sleeping problems was also found to be a risk factor for suicide in the present study. To disclose the relationship between sleep quality and suicide, further studies would be warranted.

In our study, an association between smoking and suicide was observed, but its mechanism is not clear. Two possible reasons are, smoking may play a role as medication for depression with nicotine and that depressives have higher rate of both smoking and suicide, or smoking causes physical disease and the disease to suicide ${ }^{15}$. Further study is required to clarify this mechanism.

Alcohol drinking ${ }^{17}$ have been incriminated as probable risk factors for suicide, but our study failed to find any statistically significant associations with suicide. In our study, the observed number of suicide was too small to analyze further according to the number of amount of alcohol consumption.

In conclusion, we found an association between depressive mood measured five years ago and subsequent suicide in a middle-aged workers. It is true that the rates of suicide is low and the people with depressive mood are large in the general population, but the relationship between depression and suicide will be continue for at least 5 years. Detailed observation and follow-up of those with depression should be systematically organized with due attention and caution. 


\section{ACKNOWLEDGMENT}

We are grateful to Dr. Norito Kawakami, the associate professor of Depratment of Public Health, Gifu University, School of Medicine, for his professional advise. This study was partly supported by the Ministry of Education, Science and Culture.

\section{REFERENCES}

1. Vital Statistics of Japan, 1996, Vol 3. Tokyo: Health and Welfare Statistical Association, 1996

2. Shaffer D. Suicide: risk factors and the public health. Am J Public Health 1993;83:171-2.

3. Fombonne E. Increased rates of depression: update of epidemiological findings and analytical problems. Acta Psychiatr Scand 1994;90:145-56.

4. Ross RK, Bernstein L, Trent L, Henderson BE, PaganiniHill A. A prospective study of risk factors for traumatic deaths in a retirement community. Prev Med 1990;19:323-34.

5. Zung W. A self-rating depression scale. Arch Gen Psychiatry 1965;12:63-70.

6. Wilkin D, Hallam L, MA D. Measures of mental illness and mental health. In: Measures of need and outcome for primary health care. New York: Oxford, 1992: 74-110.

7. Kawakami N, Roberts R, Lee E, Araki S. Changes in rates of depressive symptoms in a Japanese working population: life-tables analysis from a 4-year follow-up study. Psychological Medicine 1995;25:1181-1190.

8. Jick SS, Dean AD, Jick H. Antidepressants and suicide. BMJ 1995;310(6974):215-8.

9. Newman SC, Bland RC. Suicide risk varies by subtype of affective disorder. Acta Psychiatr Scand 1991;83:420-6.

10. Rorsman B, Hagnell O, Lanke J. Violent death and mental disorders in the Lundby Study. Accidents and suicides in a total population during a 25-year period. Neuropsychobiology 1982;8:233-40.

11. Barrett J, Hurst M, DiScala C, Rose R. Prevalence of depression over a 12 -month period in a nonpatient popu- lation. Arch General Psychiatry 1978;35:741-744.

12. Baris D, Armstrong BG, Deadman J, Theriault G. A case cohort study of suicide in relation to exposure to electric and magnetic fields among electrical utility workers. Occupational \& Environmental Medicine 1996;53:17-24.

13. Romanov K, Hatakka M, Keskinen E, et al. Self-reported hostility and suicidal acts, accidents, and accidental deaths: a prospective study of 21,443 adults aged 25 to 59. Psychosom Med 1994;56:328-36.

14. Graves PL, Thomas CB. Habits of nervous tension and suicide. Suicide Life Threat Behav 1991;21:91-105.

15. Hemenway D, Solnick SJ, Colditz GA. Smoking and suicide among nurses. Am J Public Health 1993;83:249-51.

16. Smith GD, Phillips AN, Neaton JD. Smoking as "independent" risk factor for suicide: illustration of an artifact from observational epidemiology? Lancet 1992;340 (8821):709-12.

17. Allebeck P, Allgulander C, Fisher LD. Predictors of completed suicide in a cohort of 50,465 young men: role of personality and deviant behaviour. BMJ 1988;297 (6642):176-8.

18. Kawachi I, Willett WC, Colditz GA, Stampfer MJ, Speizer FE. A prospective study of coffee drinking and suicide in women. Arch Intern Med 1996;156:521-5.

19. Schairer C, Adami HO, Hoover R, Persson I. Cause-specific mortality in women receiving hormone replacement therapy. Epidemiol 1997;8:59-65.

20. Iribarren C, Reed DM, Wergowske G, Burchfiel CM, Dwyer JH. Serum cholesterol level and mortality due to suicide and trauma in the Honolulu Heart Program. Arch Intern Med 1995;155:695-700.

21. Zureik M, Courbon D, Ducimetiere P. Serum cholesterol concentration and death from suicide in men: Paris prospective study I. BMJ 1996;313(7058):649-51.

22. Klatsky AL, Armstrong MA, Friedman GD. Coffee, tea, and mortality. Annal Epidemiol 1993;3:375-81.

23. Bliwise DL, Friedman L, Yesavage JA. Depression as a confounding variable in the estimation of habitual sleep time. J Clin Psychology 1993;49:471-477. 